\title{
Shielding Properties of Protective Thin Film Coatings and Blended Concrete Compositions for High Level Waste Storage Packages
}

\author{
${ }^{1}$ Michael A. Fusco, ${ }^{2}$ Leigh Winfrey, ${ }^{1}$ Mohamed A. Bourham \\ ${ }^{1}$ North Carolina State University, Department of Nuclear Engineering, Raleigh, NC 27695- \\ 7909, USA \\ ${ }^{2}$ University of Florida, Nuclear Engineering Program, Department of Materials Science and \\ Engineering, Gainesville, FL 32611-6400, USA
}

\begin{abstract}
Various thin film coatings have been proposed to protect stainless steel high level waste (HLW) containers from premature failure due to localized corrosion, hydrogen embrittlement, and mechanical wear. These coatings include TiN, $\mathrm{ZrO}_{2}, \mathrm{MoS}_{2}, \mathrm{TiO}_{2}$, and $\mathrm{Al}_{2} \mathrm{O}_{3}$, to be deposited either in multiple layers or as a thicker, single-layer composite. Linear attenuation coefficients of these materials have been simulated using MicroShield and measured experimentally for various photon energies. Additionally, spent fuel casks with overpacks made of two different types of concrete were simulated to compare exposure rate at the cask surface. In the energy range that is significant for high level waste storage all coating materials possess very similar attenuation behavior. A specialty concrete, containing magnetite $\left(\mathrm{Fe}_{3} \mathrm{O}_{4}\right)$ and lead oxide $(\mathrm{PbO})$, reduces the exposure rate at the outer surface of the overpack by several orders of magnitude. The higher- $\mathrm{Z}$ elements not present in ordinary concrete greatly increase attenuation of intermediate-energy gammas $(0.4-1.0 \mathrm{MeV})$. The thin film coatings do not affect the shielding capabilities of the HLW packaging, as their total proposed thickness is nearly three orders of magnitude less than the mean free path (MFP) of the primary photons of interest.
\end{abstract}

\section{Key words}

Shielding, protective coatings, high-level waste storage, dry cask overpack composition, concrete blending, gamma ray shielding,

Michael Fusco

Department of Nuclear Engineering, North Carolina State University, Raleigh, NC 27695-7909, USA

e-mail: mfusco@ncsu.edu

*Corresponding Author

Leigh Winfrey

University of Florida, Nuclear Engineering Program, Department of Materials Science and Engineering, Gainesville, FL 32611-6400, USA

e-mail: winfrey@mse.ufl.edu

Mohamed Bourham

Department of Nuclear Engineering, North Carolina State University, Raleigh, NC 27695-7909, USA

e-mail: bourham@ncsu.edu 


\section{Introduction}

Storage of spent nuclear fuel from commercial reactors and government-controlled high level waste (HLW) is one of the most important issues facing the nuclear industry. On-site dry cask storage is the only current long term storage option for commercial spent fuel, and thus, limiting exposure outside of the cask is of high priority. Dry storage casks consist primarily of a steel canister and concrete overpack, often with a glass layer in between (Bare and Torgerson, 2001). HLW canisters are typically made of stainless steel because of its good mechanical strength and corrosion resistance (Yim and Murty, 2000; Farmer et al., 2003; Lambert et al., 2012). However, stainless steel suffers from intergranular corrosion due to carbide buildup at grain boundaries and stress corrosion cracking (SCC) due to residual stresses from welding in the presence of chloride ions (Revie and Uhlig, 2008). Additionally, mechanical wear and embrittlement from hydrogen diffusion pose a threat to the long term integrity of spent fuel canisters. A lack of in-situ monitoring coupled with the relative unpredictability of localized corrosion and embrittlement from gas diffusion makes canister lifetime difficult to predict. The US NRC mandates that high level waste containers must remain intact for 300 - 1000 years (U.S. Nuclear Regulatory Commission, 2002), making materials research for HLW storage imperative.

In order to combat premature failure of stainless steel canisters, various thin-film coatings have been proposed (Winfrey and Bourham, 2013). These coatings include titanium nitride (TiN), molybdenum disulfide $\left(\mathrm{MoS}_{2}\right)$, and Zirconia $\left(\mathrm{ZrO}_{2}\right)$, titania $\left(\mathrm{TiO}_{2}\right)$, and alumina $\left(\mathrm{Al}_{2} \mathrm{O}_{3}\right)$ as an eventual composite, and have been shown to be good barriers to localized corrosion, hydrogen diffusion, and mechanical wear (Checchetto et al., 1996; Scheffing et al., 2006).

The middle coating layer is a composite of the three oxides, and is commonly referred to as zirconolite.

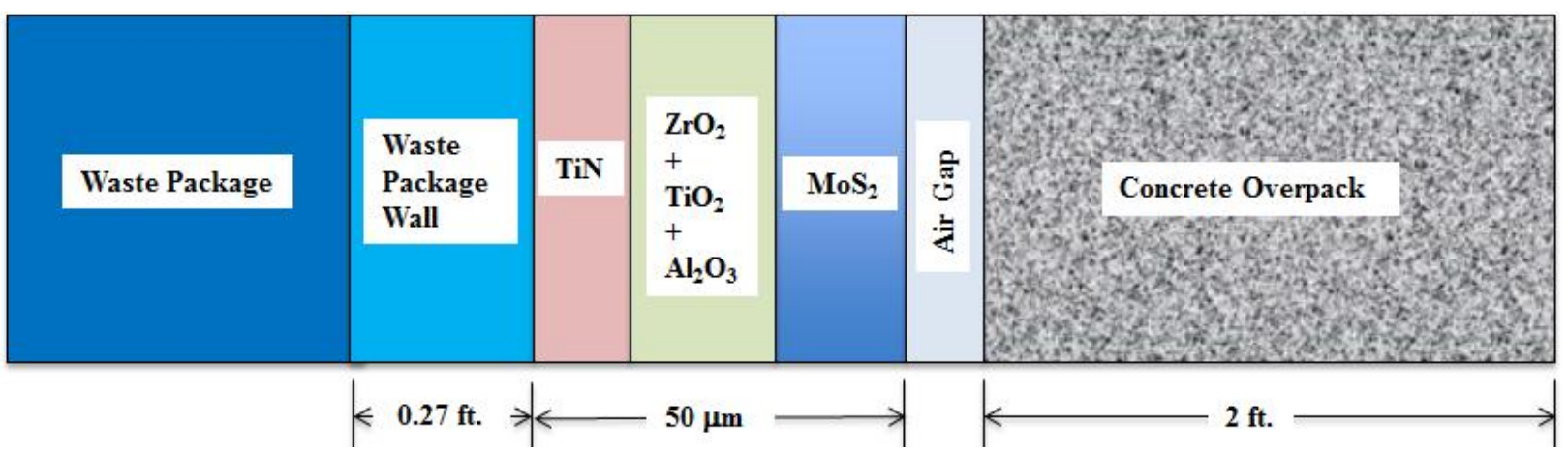

Fig. 1: Multilayer coatings for high level waste storage (not to scale)

If these coatings are to be utilized to protect HLW containers, their attenuation properties must be known. Mass attenuation coefficients provide an adequate measure of the shielding capabilities of each material. The mass attenuation coefficient is independent of density, allowing for direct comparison between materials. A simulation study on the heavy particle impact on such multi-layered coatings, as in Fig. 1, has shown that $2 \mathrm{MeV}$ particles can cause damage in the first $10 \mu \mathrm{m}$ of the TiN layer if neutrons leak through cracks and reach the coatings (Radwan et al., 2015).

Recently there has been interest in specialty concrete for radiation shielding applications. The composition of concrete can be modified using additives and different forms of aggregates, making it an ideal material to be tailored toward specific uses. A computational study on various compositions of concrete for gamma attenuation, has shown that adding magnetite $\left(\mathrm{Fe}_{3} \mathrm{O}_{4}\right)$ and lead oxide $(\mathrm{PbO})$ in specific concentrations to standard concrete increases attenuation and greatly reduces exposure rate outside the spent fuel cask (Waly and Bourham, 2015), and a specific concrete mixture, referred to as 'concrete-6' in their paper will be used as a comparison to ordinary concrete in the present study. 


\section{Methods}

\subsection{Computational Methods}

Linear attenuation coefficients are calculated using MicroShield 9.05 (GrooveSoftware, 2012). The mass attenuation coefficient is calculated from the linear attenuation coefficient divided by the mass density of the absorber material and is given by the exponential attenuation law:

$$
\frac{\mu}{\rho}=\frac{-1}{\rho x} \ln \left(\frac{I}{I_{0}}\right)
$$

Where $\mu$ is the linear attenuation coefficient $\left(\mathrm{cm}^{-1}\right), \rho$ is mass density $\left(\mathrm{g} / \mathrm{cm}^{3}\right), \mu / \rho$ is the mass attenuation coefficient $\left(\mathrm{cm}^{2} / \mathrm{g}\right), \mathrm{x}$ is the absorber thickness $(\mathrm{cm}), \mathrm{I}_{0}$ is the initial photon intensity, and $\mathrm{I}$ is the transmitted photon intensity.

MicroShield computes the theoretical attenuation coefficient at desired photon energies using material composition and density. It has also been used to assess the exposure rate outside a typical spent fuel cask, as well as to assess the change in shielding effectiveness using multilayer protective coatings and magnetite/lead oxide-doped concrete "concrete 6" (Waly and Bourham, 2015). This concrete consists of 13.98\% cement, $7.63 \%$ water, $23.5 \%$ aggregate (mainly $\mathrm{SiO}_{2}$ ), $39.195 \%$ magnetite, and $15.678 \%$ lead oxide. The complete chemical composition of this proposed concrete mixture is given in (Waly and Bourham, 2015).

The cask utilized in this study consists of a cylindrical volume of spent fuel with a height of $20 \mathrm{ft}$. and 8.727 -ft. radius. The steel canister is $0.27 \mathrm{ft}$. thick, and the concrete overpack is $2 \mathrm{ft}$. thick. Three coating layers are added to the outside of the steel canister, which combined are $50 \mu \mathrm{m}$ thick. The radiation source used in the MicroShield simulations comes from Surry plant spent fuel depleted using ORIGEN at 38.6 GWd/MTU (Naegeli, R. E., 2004) and is given in Table I. The photon activity by energy group is scaled to represent 16 MTU per storage cask. At 0.4 to 0.5 MTU per assembly in a typical PWR, this assumes between 32 and 40 assemblies per cask. This is conservative given that the NRC considers between 2 dozen and 6 dozen assemblies per cask depending on the type (U.S. Nuclear Regulatory Commission, 2015). The dose point is taken half way up the cask at the outer surface as illustrated in Fig. 2.

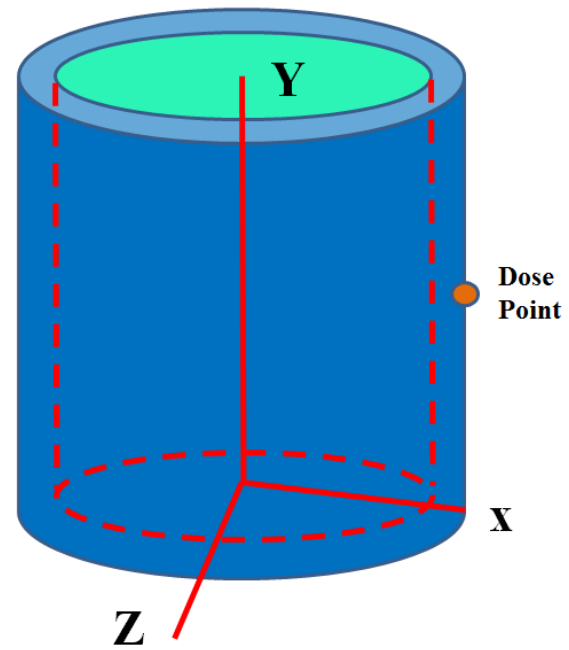

(a)

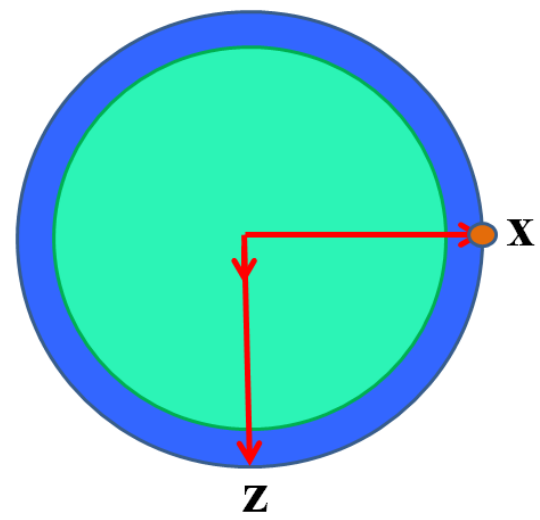

(b)

Fig. 2 Microshield cask geometry elevation (a) and top view (b) 
Table I: Source specification for spent fuel cask simulation - 38.6 GWd/MTU Surry Plant

\begin{tabular}{|c|c|c|}
\hline $\begin{array}{c}\text { Mean Photon } \\
\text { Energy (MeV) }\end{array}$ & $\begin{array}{c}\text { Activity/MTU } \\
\text { (Photons/sec) }\end{array}$ & $\begin{array}{c}\text { \% Energy } \\
\text { Activity }\end{array}$ \\
\hline 0.015 & $3.08 \mathrm{E}+09$ & 0.00000 \\
\hline 0.02 & $7.03 \mathrm{E}+09$ & 0.00000 \\
\hline 0.03 & $1.55 \mathrm{E}+14$ & 0.31680 \\
\hline 0.04 & $4.67 \mathrm{E}+13$ & 0.12730 \\
\hline 0.05 & $2.82 \mathrm{E}+12$ & 0.00960 \\
\hline 0.06 & $4.61 \mathrm{E}+13$ & 0.18850 \\
\hline 0.08 & $2.38 \mathrm{E}+12$ & 0.01300 \\
\hline 0.10 & $2.22 \mathrm{E}+13$ & 0.15130 \\
\hline 0.15 & $1.59 \mathrm{E}+10$ & 0.00020 \\
\hline 0.20 & $3.74 \mathrm{E}+12$ & 0.05100 \\
\hline 0.30 & $4.39 \mathrm{E}+11$ & 0.00900 \\
\hline 0.40 & $7.19 \mathrm{E}+11$ & 0.01960 \\
\hline 0.50 & $6.34 \mathrm{E}+11$ & 0.02160 \\
\hline 0.60 & $2.32 \mathrm{E}+15$ & 94.8505 \\
\hline 0.80 & $2.25 \mathrm{E}+13$ & 1.22650 \\
\hline 1.00 & $1.53 \mathrm{E}+13$ & 1.04250 \\
\hline 1.50 & $1.93 \mathrm{E}+13$ & 1.97260 \\
\hline 2.00 & $2.91 \mathrm{E}+06$ & 0.00000 \\
\hline Total & $2.66 \mathrm{E}+15$ & \\
\cline { 3 - 3 } & & \\
\hline
\end{tabular}

The source specification for spent fuel cask simulation shows that the $0.6 \mathrm{MeV}$ photon energy group contributes almost $95 \%$ of the energy activity, mostly from the decay of Cs-137. Also of interest are three higher energy groups: $0.8,1.0$, and $1.5 \mathrm{MeV}$, which have fairly high activity and are more difficult to shield than the lower energy gammas. These will likely contribute much of the total exposure rate. There are several energy groups in the tens of $\mathrm{keV}$ range that have high activity, but they are quite easily shielded and will not contribute significantly to exposure.

\subsection{Experimental Methods}

In order to corroborate theoretical calculations using the MicroShield code, gamma attenuation experiments have been performed. The radiation sources are 1" disks of Ba-133, Cs-137, and Co-60 to determine attenuation coefficients at four photon energies: $356 \mathrm{keV}, 661.7 \mathrm{keV}, 1173 \mathrm{keV}$, and 1332.5 $\mathrm{keV}$, respectively. The detector is a 2" x 2" sodium iodide (NaI) scintillator, with built-in photomultiplier tube (PMT) and preamplifier, connected to a high voltage power supply, shaping amplifier, and multichannel analyzer (MCA). The three gamma sources are tested separately to avoid self-shielding. The detector is placed $60 \mathrm{~cm}$ directly above the source, and the disks are placed one-third of the way between source and detector, assuring most photons reaching the detector pass through the disk. Fig. 3 illustrates the experimental set up for gamma attenuation measurements. 


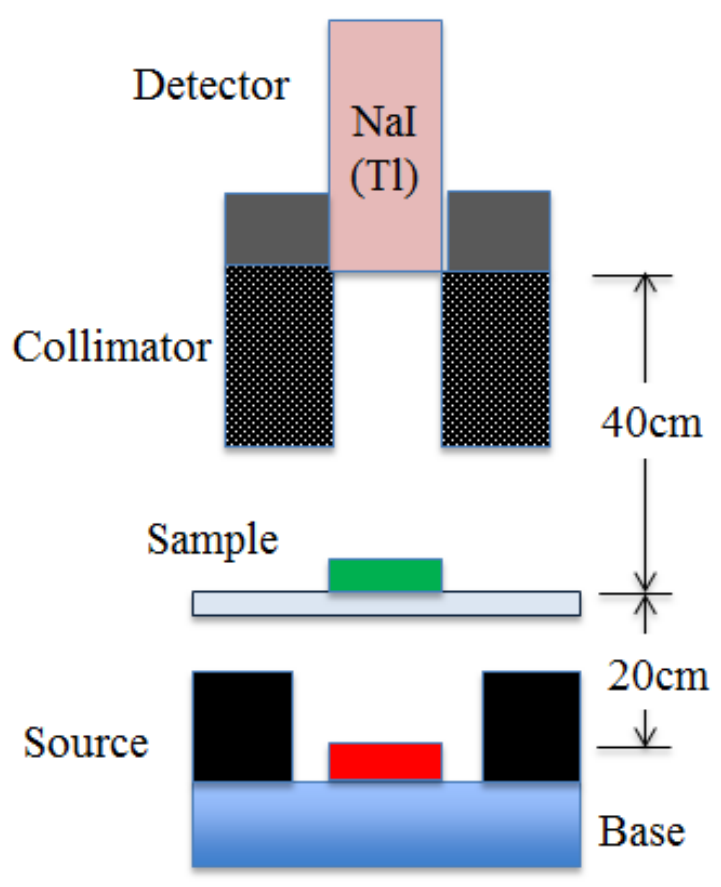

Fig. 3: Gamma attenuation experimental setup

The full energy peaks measured using the MCA software are fit to a Gaussian plus linear background using the curve fit function in Matlab, such that the fitting function takes the form:

$$
f(x)=a \cdot \exp \left(-\left(\frac{x-b}{c}\right)^{2}\right)+d x+e
$$

Where $\mathrm{a}, \mathrm{b}, \mathrm{c}, \mathrm{d}$, and e are fitting coefficients and $\mathrm{x}$ is the MCA channel number. Equation (2) is then integrated over the entire photopeak to obtain the peak area. Ratios of integrated peak areas are used to calculate linear attenuation coefficients using Equation (3):

$$
\mu=\frac{1}{x} \ln \left(\frac{A_{0}}{A}\right)
$$

Where: $\quad \mathrm{A}_{0}$ is the integrated photopeak area with no attenuation sample in place, $\mathrm{A}$ is the integrated photopeak area with the sample present,

And $\quad \mathrm{x}$ is the thickness of the steel disk 


\section{Materials}

Densities of the materials studied are given in Fig. 4, which includes the substrate materials of type 304 and type 316 stainless steel and the coating materials $\left(\mathrm{TiN}, \mathrm{ZrO}_{2}, \mathrm{MoS}_{2}, \mathrm{TiO}_{2}, \mathrm{Al}_{2} \mathrm{O}_{3}\right.$ and Zirconolite), in addition to the blended concrete 6 and the ordinary concrete. Zirconolite in this study is a stoichiometric combination of $\mathrm{ZrO}_{2}, \mathrm{TiO}_{2}$, and $\mathrm{Al}_{2} \mathrm{O}_{3}$, although the relative compositions of each oxide may be altered to create more desirable properties.

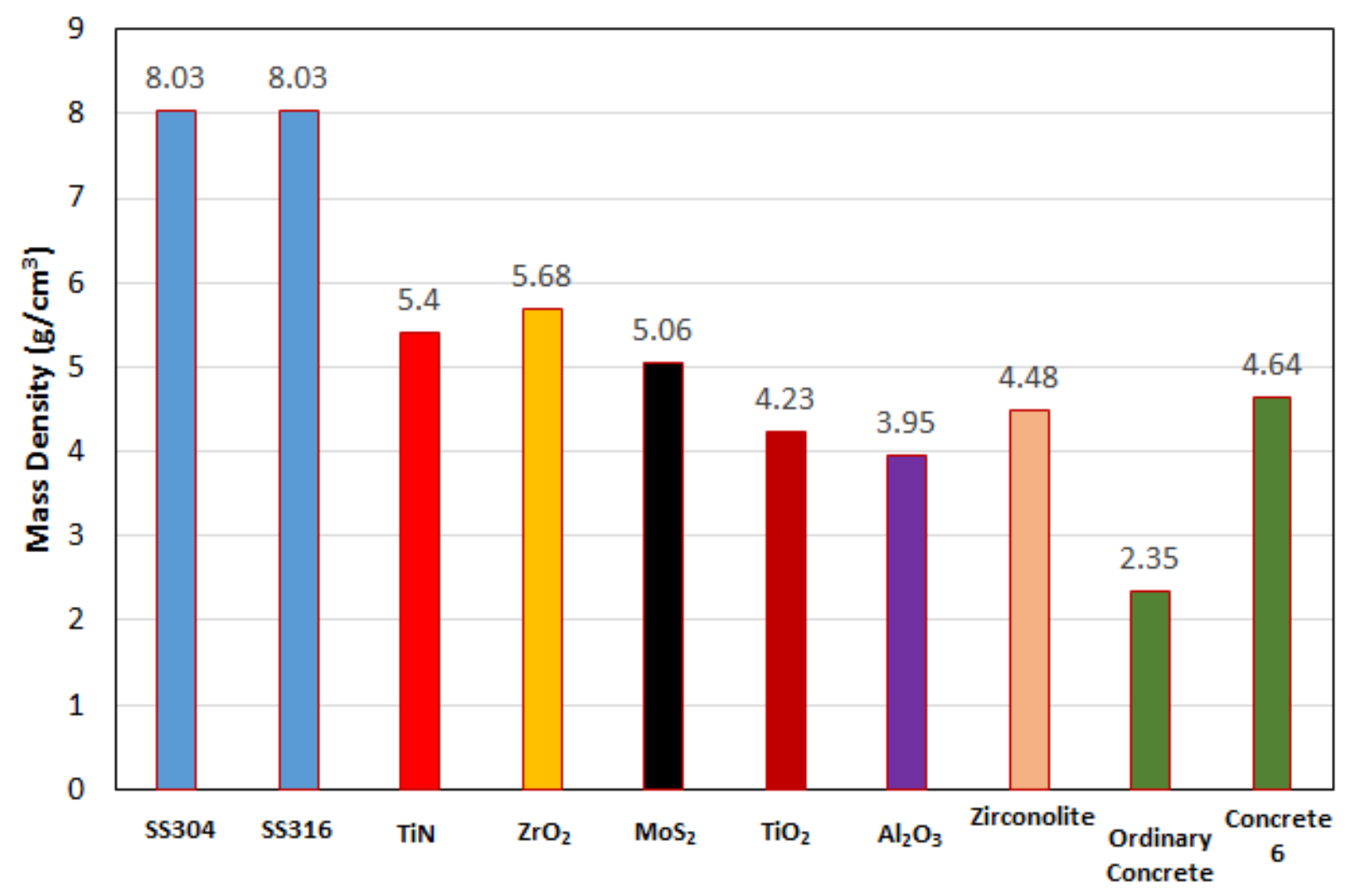

Fig. 4: Mass density of materials used in this study

The samples tested are 1" diameter steel disks, both bare and coated. Thin film coatings are achieved using magnetron sputter deposition. The stainless steel substrates are two different thicknesses: stainless steel type 304 is $0.8975 \mathrm{~mm}$ thick and stainless steel type 316 is $1.498 \mathrm{~mm}$ thick. Focused ion beam (FIB) techniques reveal the coatings to be no thicker than several hundred nanometers. The oxide coatings, which sputter very slowly, are all less than $100 \mathrm{~nm}$ thick, whereas titanium nitride has the fastest deposition rate with a maximum thickness of roughly $900 \mathrm{~nm}$. 


\section{Results and Discussion}

\subsection{Linear Attenuation Coefficient}

The linear attenuation coefficients for the materials studied were calculated from measurements obtained using the setup in Fig. 3. The attenuation coefficients are displayed in Fig. 5 with 95\% confidence bounds, which correspond to the confidence bounds of the coefficients of the curve fit (Equation (2)). Standard error using Poisson statistics was also determined for each value of linear attenuation, but the curve fitting produces greater uncertainty than the experiment itself. Stainless steel type 304 and 316 have very similar compositions and thus have nearly identical attenuation properties. The attenuation of type 316 stainless steel is presented rather than type 304 because the disks are thicker, allowing for more precise measurement of the linear attenuation coefficient. Moreover, only the titanium nitride coating on stainless steel type 316 was chosen to represent the coated steels because it is the thickest coating on the thickest substrate, thus giving the best opportunity to measure a difference in attenuation from the bare steel.

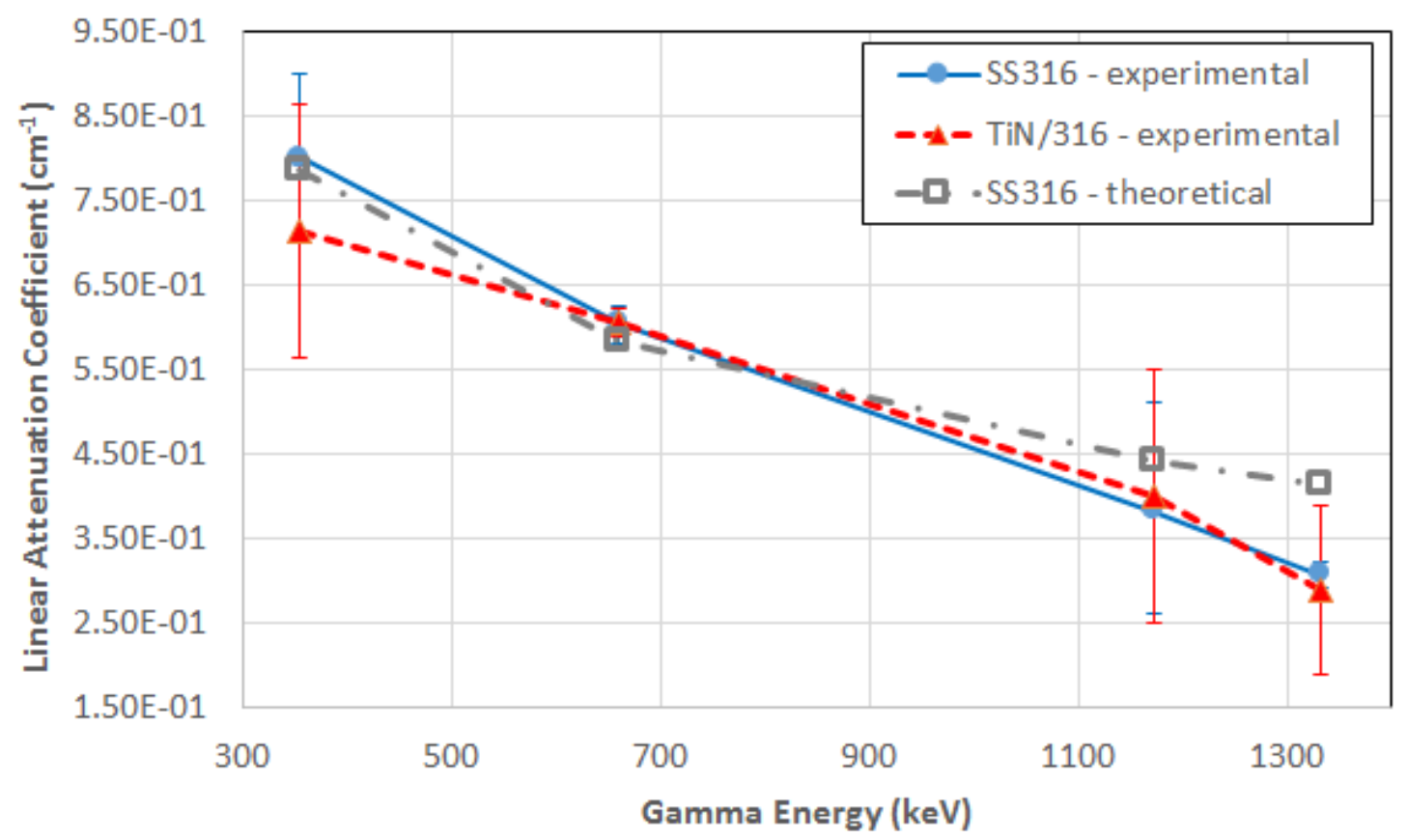

Fig. 5: Comparison of experimental linear attenuation coefficients as a function of incident gamma energy for bare and TiN-coated stainless steel 316 with theoretical values

Experimental linear attenuation coefficients for stainless steel type 316 at four distinct incident photon energies are similar to predicted values. In all but one case, the theoretical value lies within the $95 \%$ confidence band of the experimental value. It lies outside the confidence range for the $1332.5 \mathrm{keV}$ Co-60 gamma ray. Higher energy gammas require greater thickness to accurately measure the attenuation. The attenuation value for $662 \mathrm{keV}$ gammas is both accurate and precise because the photopeak suffers neither from low signal-to-noise ratio (as with the Co-60 peaks) nor having other peaks close by to convolute the analysis. The titanium nitride coating, as well as all other coating materials, does not significantly affect the attenuation of the stainless steel substrate. It was not possible to measure the attenuation of the TiN separate from the steel because of the film thickness. The theoretical linear 
attenuation coefficient for TiN is $0.392 \mathrm{~cm}^{-1}$ for $661.7 \mathrm{keV}$ gammas. Calculating this value from experimental data for a $1 \mu \mathrm{m}$-thick coating amounts to a difference of less than $0.004 \%$ between photopeak areas, which is well within the uncertainty bounds for radiation detection.

\subsection{Mass Attenuation Coefficient and Mean Free Path}

The mass attenuation coefficients for the coatings based on MicroShield calculations are given in Fig. 6. As expected, over most of the energy spectrum the mass attenuation coefficient for each coating compound decreases monotonically. The increase in mass attenuation coefficient of $\mathrm{ZrO}_{2}$ and $\mathrm{MoS}_{2}$ in the low energy range corresponds to the $\mathrm{K}$-edge. The $\mathrm{K}$ shell binding energies for $\mathrm{Zr}$ and Mo are $18 \mathrm{keV}$ and $20 \mathrm{keV}$, respectively (Larkins, 1977). Photoelectric absorption becomes more efficient when the incident photon energy approaches the binding energy of the appropriate electron shell, which causes the observed peak in attenuation coefficient. The other elements present $(\mathrm{Ti}, \mathrm{Al}, \mathrm{O}$, and $\mathrm{N}$ ) have $\mathrm{K}$-shell binding energies in the few-keV range. Mass attenuation coefficients are very similar among coating materials in the energy range of interest for nuclear waste applications.

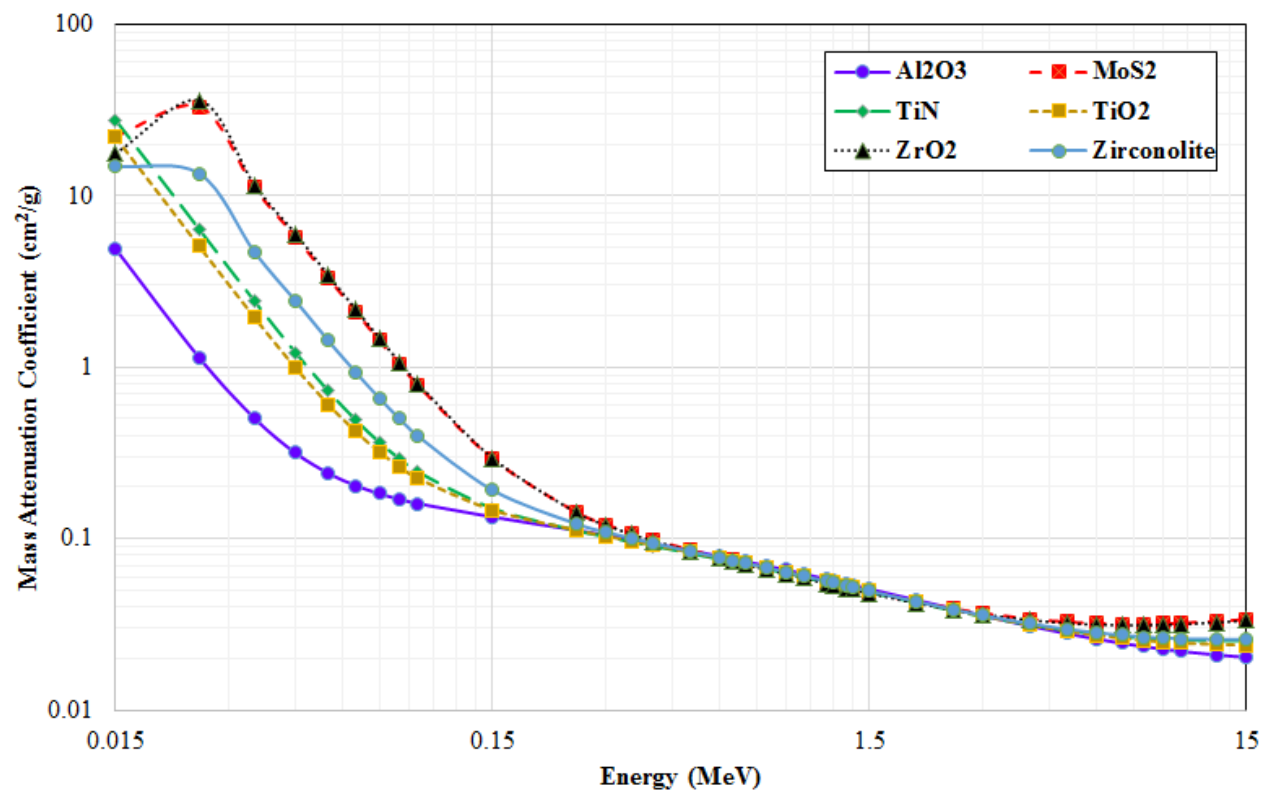

Fig. 6: Mass attenuation coefficient as a function of energy for coating materials

Based on the predicted attenuation coefficients, the mean free path (MFP) in each material as a function of incident photon energy has been calculated and is shown in Fig. 7. The minimum MFP in any of the coating materials is $50 \mu \mathrm{m}$, which occurs for $0.025 \mathrm{MeV}(25 \mathrm{keV})$ photons in zirconia. The entire multilayer coating system is proposed to be $50 \mu \mathrm{m}$ thick, so the coatings together will constitute less than a single MFP for even the lowest energy photons. A majority of the source activity stems from photons with a mean energy of $600 \mathrm{keV}$ (Table I). The MFP for these photons is between 2 and $3.5 \mathrm{~cm}$ depending on the material. This is nearly 1000 times larger than the total multilayer coating thickness, thus it is safe to assume that buildup will not be an issue for these coating materials. 


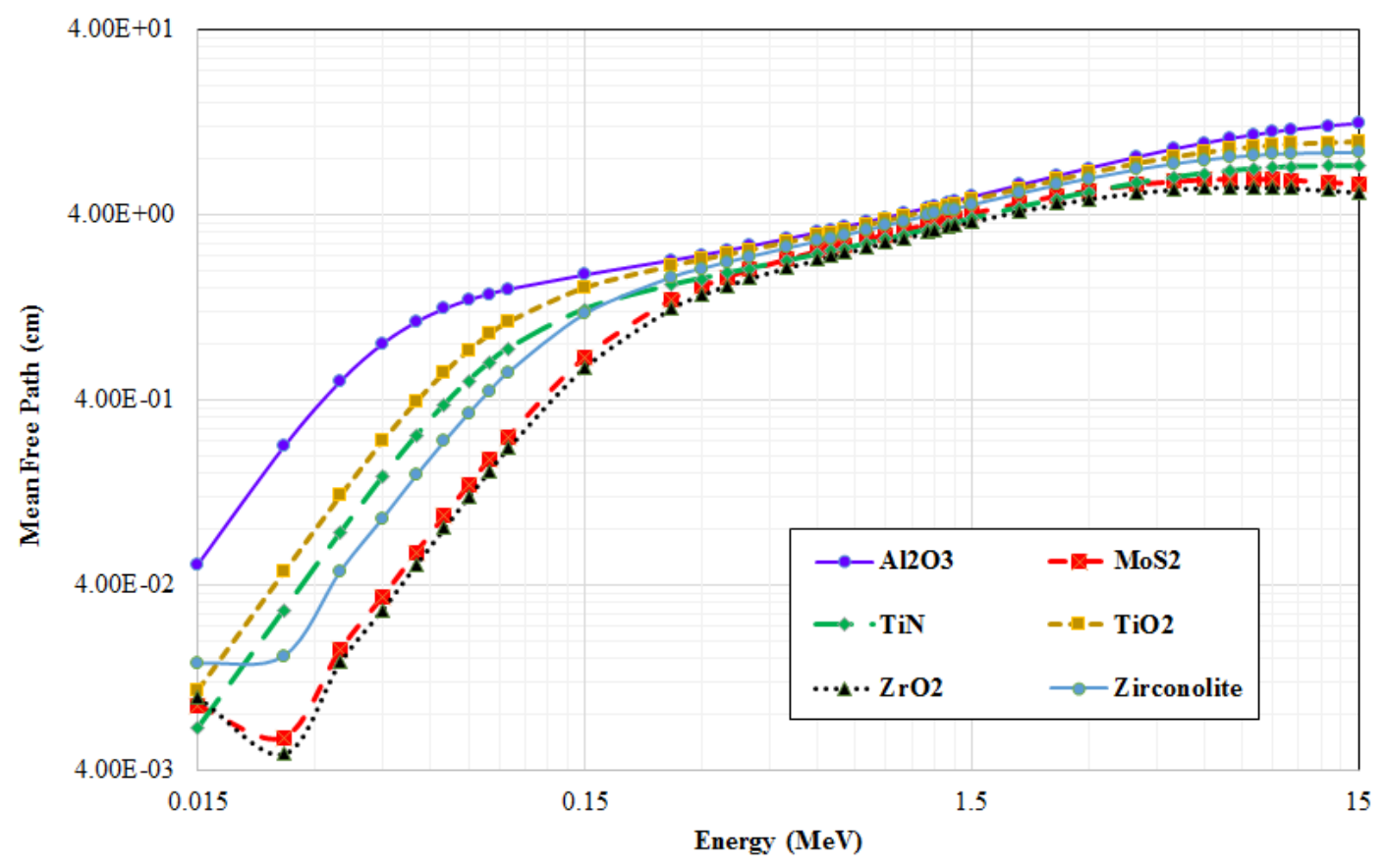

Fig. 7: Mean free path in coating materials as a function of energy

\subsection{Exposure Rate}

The exposure rate, in $\mathrm{mR} / \mathrm{hr}$, taken at the outer surface of the storage cask is several orders of magnitude lower using $2 \mathrm{ft}$. of concrete- 6 rather than ordinary concrete, as is seen in Fig. 8 . The attenuation of concrete- 6 is much better than ordinary concrete, especially above $0.3 \mathrm{MeV}$ incident photon energy. The higher- $Z$ elements not present in ordinary concrete greatly increase attenuation of intermediate-energy gammas $(0.4-1.0 \mathrm{MeV})$. Fig. 9 shows that the effectiveness of concrete-6 over ordinary concrete is maximized for photons between 0.4 and $0.6 \mathrm{MeV}$, which is where the ratio of exposure rate between the two overpack materials is at a minimum. This is the energy range into which a majority of photons emitted from spent fuel fall, according to Table I. The coatings proposed for the outer surface of the steel canister have a negligible impact on the exposure rate. The total coating thickness of $50 \mu \mathrm{m}$ is several orders of magnitude less than the MFP of the gammas of interest, as was discussed in the previous section.

Concrete- 6 proves to be increasingly more effective at shielding gammas than ordinary concrete as the thickness of the dry cask overpack increases. An overpack thickness of $5 \mathrm{ft}$. of ordinary concrete is necessary to reduce the exposure rate outside the cask to the same level as $2.5 \mathrm{ft}$. of concrete- 6 . The total exposure rate as a function of the overpack thickness is shown in Fig. 10. 


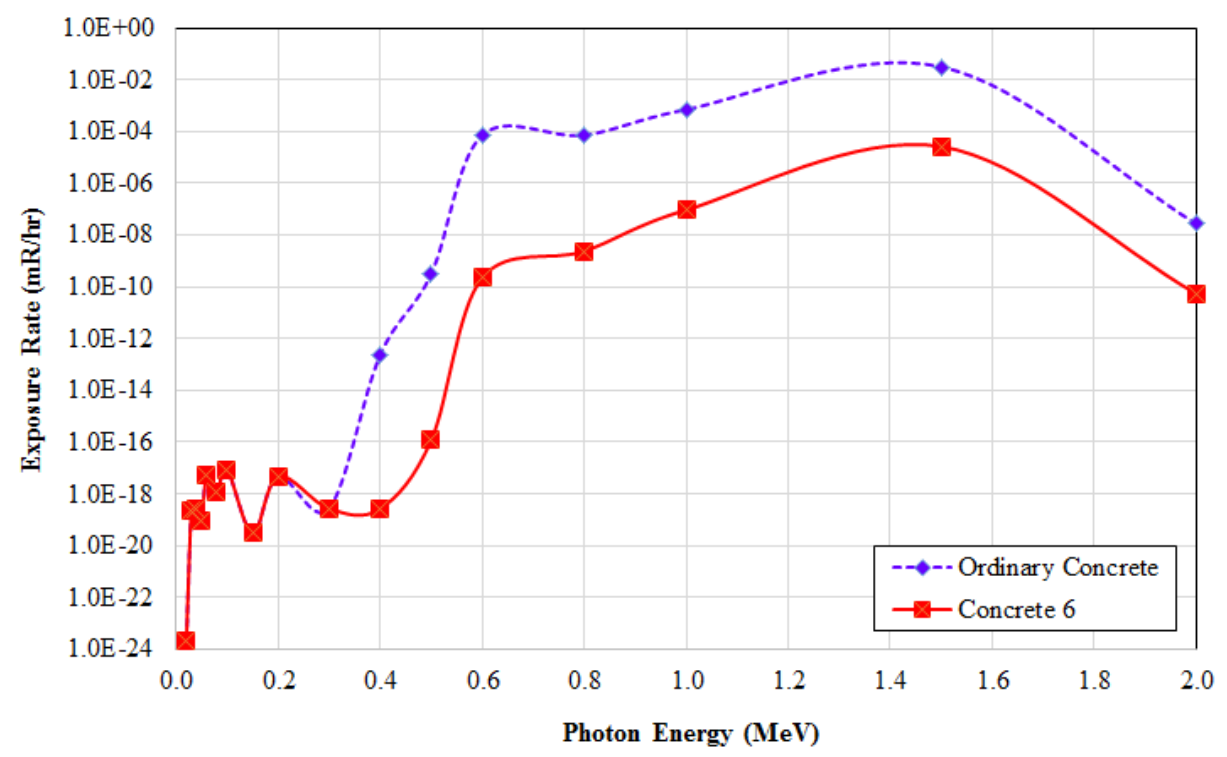

Fig. 8: Exposure rate at cask surface as a function of incident photon energy - concrete comparison

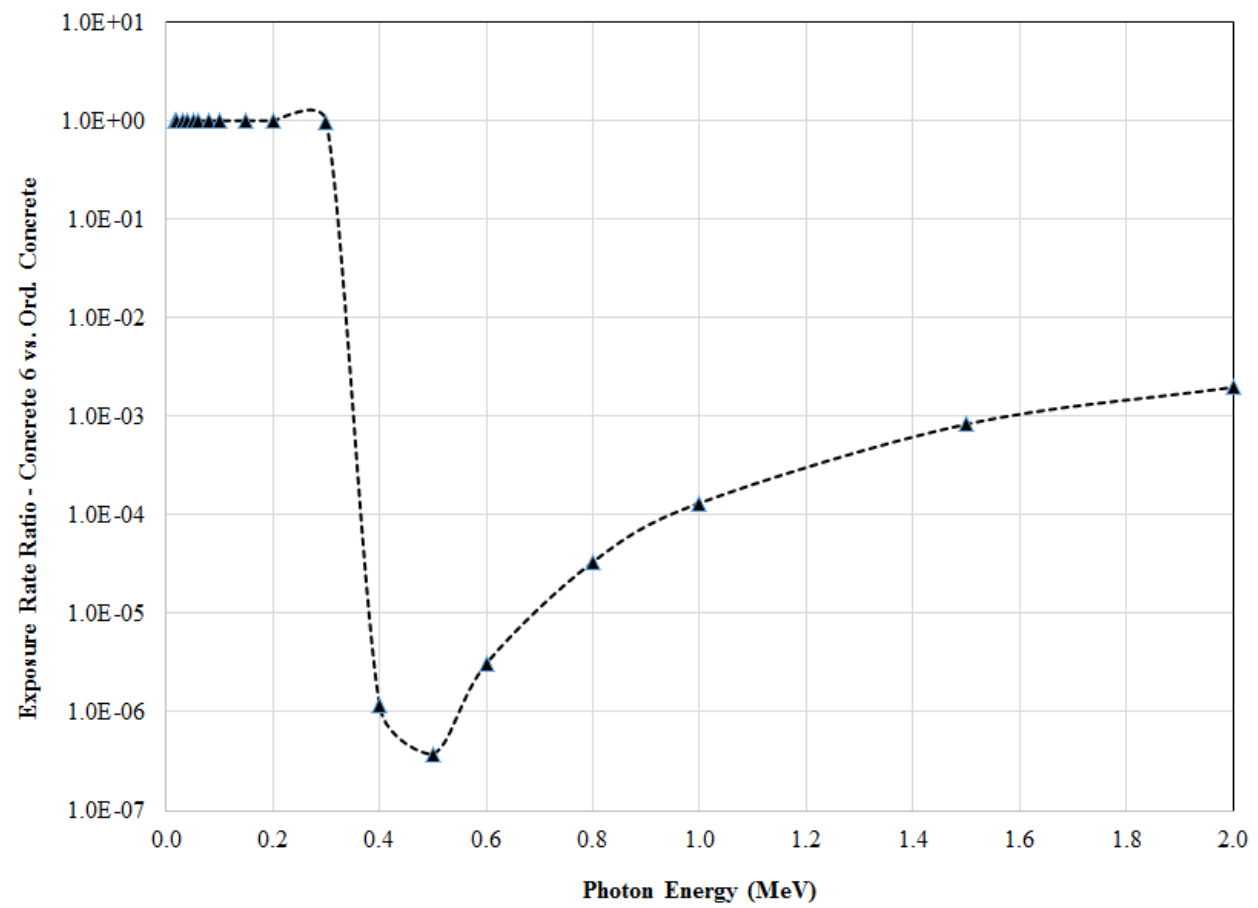

Fig. 9: Ratio of exposure rate as a function of incident photon energy - Concrete 6 versus ordinary concrete 


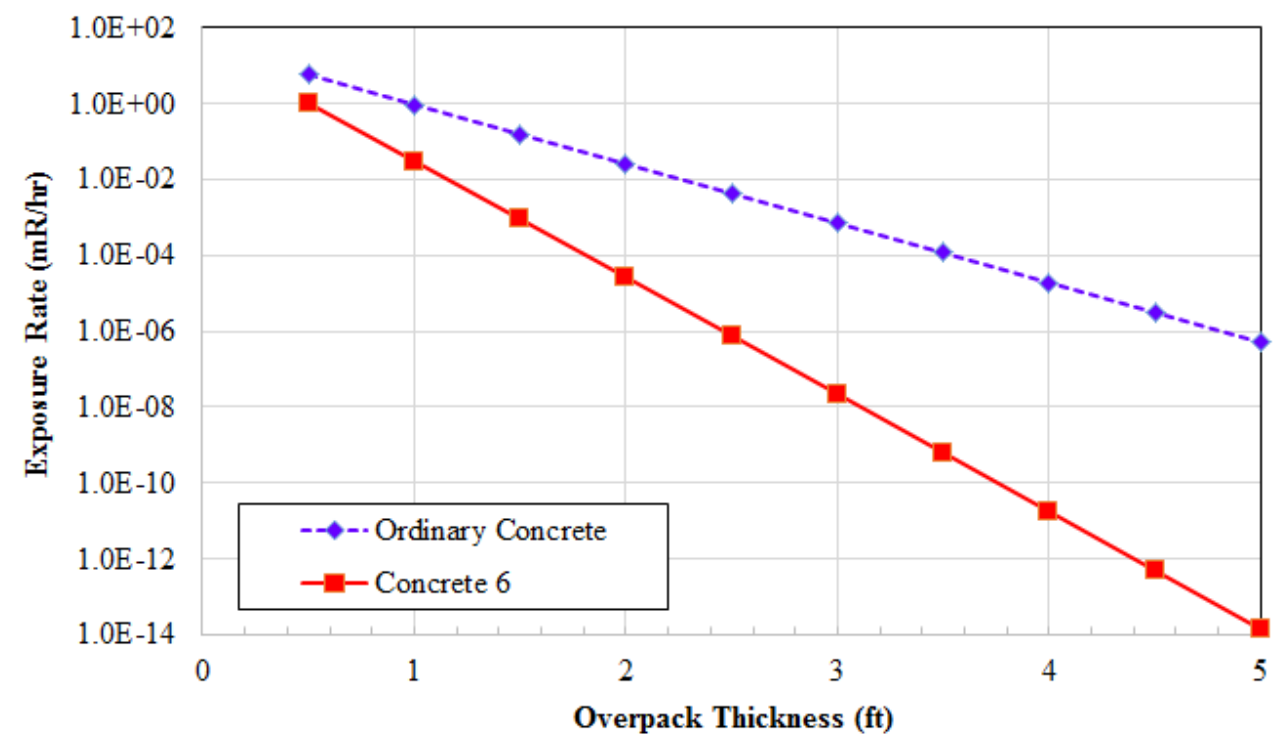

Fig. 10: Exposure rate as a function of overpack thickness (log scale)

\section{Conclusion}

The shielding properties of thin films to be deposited on stainless steel for protection against localized corrosion, hydrogen diffusion, and mechanical wear have been investigated. Microshield calculations showed mass attenuation coefficients to be nearly identical among coating materials in the energy range of interest for shielding $(0.4 \mathrm{MeV}-1.5 \mathrm{MeV})$. Experimental measurements show good agreement with predicted attenuation coefficients, based on material properties, for the bare stainless steel type 316. Coated steels show very similar attenuation to the bare substrate, which is expected based on the submicron thickness of each single-layer coating. The MFP of $0.6 \mathrm{MeV}$ gammas in these materials is between 2 and $3.5 \mathrm{~cm}$, and buildup in the coatings is negligible based on the proposed thickness of $50 \mu \mathrm{m}$. Based on full cask simulations using Microshield, the five coating materials discussed previously (TiN, $\mathrm{ZrO}_{2}, \mathrm{TiO}_{2}, \mathrm{Al}_{2} \mathrm{O}_{3}$, and $\mathrm{MoS}_{2}$ ) do not affect the exposure rate outside the cask to any measurable degree. Whereas these coatings do not provide additional shielding, they can be utilized for HLW storage without adversely affecting the shielding properties of the storage container.

Also in this study, a specialized type of concrete (concrete-6) containing $\mathrm{Fe}_{3} \mathrm{O}_{4}$ and $\mathrm{PbO}$, introduced in a published work (Waly and Bourham, 2015), was compared to ordinary concrete as an overpack material. Based on simulations, concrete- 6 is able to decrease the total exposure rate outside a typical spent fuel cask by nearly three orders of magnitude. Double the thickness of ordinary concrete is required to achieve the same exposure rate as concrete-6. Given that there has yet to be a permanent storage solution for HLW and commercial spent nuclear fuel, a specialty concrete similar to concrete-6 warrants additional investigation into the feasibility of its use as shielding for HLW containers.

\section{Acknowledgment}

Work supported by the US Department of Energy under contract DE-NE0000736 Project NEUP 13-5427 


\section{References}

Bare, W.C., Torgerson, L.D., September 2001. Dry cask storage characterization CASTOR V / 21 Cask opening and examination., NRC Rep. (NUREG/CR-6745), http://www.nrc.gov/reading$\mathrm{rm} /$ doc-collections/nuregs/contract/cr6745/

Checchetto, R., Bonelli, M., Gratton, L., Miotello,A., Sabbioni, A., Guzman, L., Horino, Y., Benamati, G. (1996). Analysis of the hydrogen permeation properties of TiN-TiC bilayers deposited on martensitic stainless steel. Surface and Coatings Technol., 83(1-3), 40-44.

Farmer, J., et al. (2003). Technical Basis Document No. 6: Waste Package and Drip Shield Corrosion. Technical Report, UCRL-LR-155288, TRN: US0305613, Lawrence Livermore National Lab. https://inis.iaea.org/search/search.aspx?orig_q=RN:35007508

GrooveSoftware. (2012). MicroShield. Retrieved from http://radiationsoftware.com/microshield/

Lambert, J. D., Bakhtiari, S., Bodnar, I., Kot, C., \& Pence, J. (2012). NRC Job Code V6060: Extended InSitu and Real Time Monitoring Task 3: Long-Term Dry Cask Storage of Spent Nuclear Fuel.

Larkins, F. P. (1977). Semiempirical auger-electron energies for elements $10<Z<100$. Atomic Data and Nuclear Data Tables, 20, 311.

Naegeli, R. E. (2004). Calculation of the radionuclides in PWR spent fuel samples for SFR experiment planning. Sandia National Laboratories, SAND2004-2757, http://prod.sandia.gov/techlib/accesscontrol.cgi/2004/042757.pdf

Radwan, S., Winfrey, L., Bourham, M. (2015). Simulation of particle impact on protective coating of high-level waste storage packages. Progress in Nuclear Energy JPNE, 81, 196-202.

Revie, R. W. and Uhlig, H. H. (2008). Corrosion and Corrosion Control (4th ed.). John Wiley \& Sons.

Scheffing, C. C., Jagannadham, K., Yim, M. S. and Bourham, M. (2006). Properties of titanium-nitride for high-level waste packaging enhancement management and disposal . Rad. Waste Mgmt. Disposal, 156, 213-221.

U.S. Nuclear Regulatory Commission. (2002). Radioactive Waste: Production, Storage, Disposal; NUREG/BR-0216, Rev. 2.

U.S. Nuclear Regulatory Commission. (2015). Typical Dry Cask Storage System. Retrieved from http://www.nrc.gov/waste/spent-fuel-storage/diagram-typical-dry-cask-system.html

Waly, E.,and Bourham, M. (2015). Comparative study of different concrete composition as gamma-ray shielding materials. Annals of Nuclear Energy, 85, 306-310. http://doi.org/10.1016/j.anucene.2015.05.011

Winfrey, A. L. and Bourham, M. A. (2013). Enhanced shielding performance of HLW storage packages via multi-component coatings, DOE NEUP 2013 R\&D Awards, https://inlportal.inl.gov/portal/server.pt/community/neup_home/600/fy13_r_d_awards

Yim, M.S. and Murty, K. L. (2000). Materials issues in nuclear-waste management. Jom, 52(9), $26-29$. http://doi.org/10.1007/s11837-000-0183-0 